\title{
Targeted drugs for pulmonary arterial hypertension: a network meta-analysis of 32 randomized clinical trials
}

This article was published in the following Dove Press journal:

Patient Preference and Adherence

8 May 2017

Number of times this article has been viewed

\author{
Xiao-Fei Gao' \\ Jun-Jie Zhang ${ }^{1,2}$ \\ Xiao-Min Jiang' \\ Zhen $\mathrm{Ge}^{1,2}$ \\ Zhi-Mei Wang' \\ Bing $\mathrm{Li}^{\prime}$ \\ Wen-Xing Mao' \\ Shao-Liang Chen ${ }^{1,2}$ \\ 'Department of Cardiology, Nanjing \\ First Hospital, Nanjing Medical \\ University, Nanjing, ${ }^{2}$ Department of \\ Cardiology, Nanjing Heart Center, \\ Nanjing, People's Republic of China
}

Background: Pulmonary arterial hypertension (PAH) is a devastating disease and ultimately leads to right heart failure and premature death. A total of four classical targeted drugs, prostanoids, endothelin receptor antagonists (ERAs), phosphodiesterase 5 inhibitors (PDE-5Is), and soluble guanylate cyclase stimulator (sGCS), have been proved to improve exercise capacity and hemodynamics compared to placebo; however, direct head-to-head comparisons of these drugs are lacking. This network meta-analysis was conducted to comprehensively compare the efficacy of these targeted drugs for PAH.

Methods: Medline, the Cochrane Library, and other Internet sources were searched for randomized clinical trials exploring the efficacy of targeted drugs for patients with PAH. The primary effective end point of this network meta-analysis was a 6-minute walk distance (6MWD). Results: Thirty-two eligible trials including 6,758 patients were identified. There was a statistically significant improvement in $6 \mathrm{MWD}$, mean pulmonary arterial pressure, pulmonary vascular resistance, and clinical worsening events associated with each of the four targeted drugs compared with placebo. Combination therapy improved 6MWD by $20.94 \mathrm{~m}(95 \%$ confidence interval [CI]: 6.94, 34.94; $P=0.003)$ vs prostanoids, and 16.94 m (95\% CI: 4.41, 29.47; $P=0.008)$ vs ERAs. PDE-5Is improved 6MWD by $17.28 \mathrm{~m}$ (95\% CI: $1.91,32.65 ; P=0.028)$ vs prostanoids, with a similar result with combination therapy. In addition, combination therapy reduced mean pulmonary artery pressure by $3.97 \mathrm{mmHg}(95 \% \mathrm{CI}:-6.06,-1.88 ; P<0.001)$ vs prostanoids, $8.24 \mathrm{mmHg}(95 \% \mathrm{CI}:-10.71,-5.76 ; P<0.001)$ vs ERAs, $3.38 \mathrm{mmHg}(95 \% \mathrm{CI}:-6.30,-0.47$; $P=0.023)$ vs PDE-5Is, and $3.94 \mathrm{mmHg}(95 \% \mathrm{CI}:-6.99,-0.88 ; P=0.012)$ vs sGCS. There were no significant differences in all-cause mortality and severe adverse events between prostanoids, ERAs, PDE-5Is, sGCS, combination therapy, and placebo.

Conclusion: All targeted drugs for PAH are associated with improved clinical outcomes, especially combination therapy. However, all these drugs seem to show less favorable effects on survival in the short-term follow-up, suggesting further clinical trials are required.

Keywords: pulmonary arterial hypertension, targeted drugs, 6-minute walk distance, prostanoids, network meta-analysis

\section{Introduction}

Pulmonary arterial hypertension (PAH) is a life-threatening disease associated with elevated pulmonary vascular resistance (PVR), ultimately leading to right heart failure and premature death. ${ }^{1}$ Recent data from the National Institutes of Health in the United States $^{2}$ showed that the five-year survival rate from the time of a diagnostic rightsided heart catheterization was only $57 \%,{ }^{3}$ and the treatments for PAH were very limited and expensive. Apart from the use of support measures (such as long-term
Correspondence: Shao-Liang Chen Department of Cardiology, Nanjing First Hospital, Nanjing Medical University, 68 Changle Road, 210006 Nanjing, People's Republic of China Tel/fax +86255220 8048 Email chmengx@।26.com 
oxygen therapy, diuretics, oral anticoagulants, and digoxin), targeted therapies including prostanoids, endothelin receptor antagonists (ERAs), phosphodiesterase 5 inhibitors (PDE-5Is), and soluble guanylate cyclase stimulator (sGCS) are also recommended by current guidelines and expert consensus. ${ }^{1,4,5}$ These targeted drugs have been proven to alleviate symptoms and to improve exercise capacity and hemodynamics compared to placebo by several randomized controlled clinical trials (RCTs) ${ }^{6-11}$ and meta-analyses. ${ }^{12-14}$ However, direct head-to-head comparisons are lacking, and traditional meta-analysis methods do not allow adequate assessment of the comparative effectiveness of all therapies. Therefore, we performed this network meta-analysis of all relevant randomized clinical trials to comprehensively compare the efficacy of targeted drugs for PAH treatment.

\section{Methods}

\section{Literature search}

Literature comparing targeted drugs for patients with $\mathrm{PAH}$ was acquired through searching Medline, EMBASE, and Cochrane Controlled Trials Registry data from January 1990 to December 2015. In order to search and include all relevant studies, we used combinations of various key words, including: pulmonary arterial hypertension, pulmonary hypertension, prostanoids, prostacyclin analogues, ERAs, PDE-5Is, sGCS, epoprostenol, iloprost, beroprost, treprostinil, bosentan, ambrisentan, macitentan, sildenafil, tadalafil, vardenafil, riociguat, and clinical trial. References from reviews and selected articles were further screened.

\section{Inclusion and exclusion criteria}

The inclusion criteria were: 1) the study was a RCT; 2) the sample population was definitely diagnosed as PAH according to current guidelines; 3 ) at least one of the prostanoids (epoprostenol, iloprost, beroprost, and treprostinil), ERAs (bosentan, ambrisentan, and macitentan), PDE-5Is (sildenafil, tadalafil, and vardenafil), sGCS (riociguat), and combination therapy were used, regardless of drug dosage forms; and 4) there was at least 8 weeks clinical follow-up. The following were excluded: 1) non-English language studies; 2) studies with duplicate publication, or different studies from the same sample origin; 3 ) crossover, $2 \times 2$ factorial, and pediatric studies; and 4) studies of sitaxsentan as it has been withdrawn from the market due to severe liver toxicity.

\section{Data extraction and quality assessment}

All relevant articles were independently reviewed by two investigators ( GXF and ZJJ) to assess the eligibility of the article and abstract with standardized data abstraction forms, and disagreement was resolved by a third investigator (JXM). The following data were extracted from each included study: study's name, first author, publication date, baseline demographics, and clinical outcomes at follow-up. The quality of the retrieved studies was assessed by Jadad score. ${ }^{15}$

\section{Study end points}

The primary effective end point of this network meta-analysis was a 6-minute walk distance (6MWD). The secondary end points included mean pulmonary arterial pressure (mPAP), PVR, all-cause mortality, and clinical worsening events. The definitions of clinical worsening events were slightly different across studies, and we used the trial-specific definitions for each study. The safety end point was severe adverse events (SAEs), mainly including PAH-related adverse events and treatment-related adverse events.

\section{Statistical analysis}

This network meta-analysis was conducted with Stata software 14.0 (StataCorp, College Station, TX, USA) using the network family of commands. ${ }^{16-19}$ The network meta-analysis was performed to obtain estimates for outcomes of primary and secondary end points, presented as odds ratios (OR) for dichotomous variables or weighted mean differences (WMD) for continuous variables with $95 \%$ confidence intervals (CIs). The plot of a network of drugs was a visual representation of the evidence base and offered a concise description of its characteristics. It consisted of nodes representing the drugs being compared and edges representing the available direct comparisons (comparisons evaluated in at least one study) between pairs of drugs. ${ }^{16}$ The common heterogeneity was explored in every network by comparing the magnitude of the $\tau$ value for the network with an empirical distribution of heterogeneity variances specific to the types of outcome and treatments. An inconsistency model was used only when the $P$-value of $\chi^{2}$ test was more than 0.05 . Otherwise, a consistency model was performed. ${ }^{17,19}$ A node-splitting method was also used, separating evidence for a particular comparison into direct and indirect evidence, excluding one direct comparison at a time, and estimating the indirect treatment effect for the excluded comparison. ${ }^{18}$ All $P$-values were two-tailed with the statistical significance set at $<0.05$.

\section{Results}

\section{Eligible studies and patient characteristics} Thirty-two eligible studies ${ }^{2,6-11,20-44}$ including a total of 6,758 patients, were identified in the present network meta-analysis (Figure S1). The quality of each study was good according to the Jadad score. 
The baseline characteristics are summarized in Table S1. Four important classes of drugs for PAH (prostanoids, ERAs, PDE-5Is, and sGCS) and combination therapy were compared with placebo and with each other. Networks of eligible comparisons for the primary outcomes (6MWD) are presented in Figure 1. Most enrolled patients were female and in the New York Heart Association/World Health Organization (NYHA/WHO) Functional Class II/III. The predominant etiology was idiopathic and/or familial $\mathrm{PAH}$, and the median period of study follow-up was 16 weeks (range from 8 to 115 weeks).

\section{MWD}

A 6MWD was reported in 32 RCTs. As shown in Figure 2A, there was a statistically significant improvement in 6MWD associated with each of the four drug classes compared with placebo, with a consistency model used ( $\left.\tau=8.72, \chi^{2}=7.79, P=0.455\right)$. Prostanoids, ERAs, and sGCS showed a comparable 6MWD for PAH patients. Compared with prostanoids, PDE-5Is improved 6MWD by $17.28 \mathrm{~m}(95 \% \mathrm{CI}: 1.91,32.65 ; P=0.028)$, meanwhile combination therapy improved it by $20.94 \mathrm{~m}$ (95\% CI: 6.94, 34.94; $P=0.003)$. Furthermore, combination therapy was superior to ERAs for improving 6MWD by $16.94 \mathrm{~m}$ (95\% CI: 4.41, 29.47; $P=0.008$ ).

In 22 studies, oral targeted drugs including oral prostanoids, oral ERAs, oral PDE-5Is, sGCS, and combination therapy were also associated with a more improved 6MWD than placebo, with a consistency model used $\left(\tau=7.37, \chi^{2}=11.2\right.$, $P=0.130$; Figure 2B). Compared with oral prostanoids, oral PDE-5Is and combination therapy improved 6MWD by

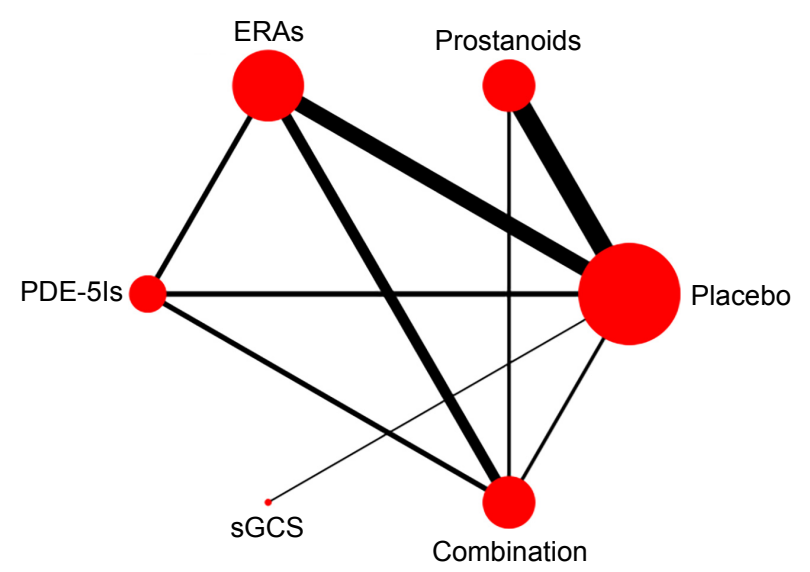

Figure I Network of available drugs for PAH.

Note: The size of nodes is proportional to the number of individuals randomized to each treatment, and the thickness of lines to the number of direct comparisons in trials.

Abbreviations: ERAs, endothelin receptor antagonists; PAH, pulmonary arterial hypertension; PDE-5ls, phosphodiesterase 5 inhibitors; sGCS, soluble guanylate cyclase stimulator.
27.53 m (95\% CI: $9.29,45.77 ; P=0.003)$ and $30.62(95 \%$ CI: $10.99,50.25 ; P=0.002)$, respectively.

\section{Mean pulmonary artery pressure and pulmonary vascular resistance}

There were significant reduced $\mathrm{mPAP}$ found in prostanoids, ERAs, PDE-5Is, sGCS, and combination therapy (17 studies, Figure $3 \mathrm{~A})$, with an inconsistency model used $\left(\tau=0.27, \chi^{2}=8.65\right.$, $P=0.003)$. ERAs increased mPAP by $4.27 \mathrm{mmHg}(95 \% \mathrm{CI}$ : $1.03,7.51 ; P=0.010)$ than prostanoids, while PDE-5Is had a similar mPAP change compared with prostanoids, ERAs, and sGCS. In addition, combination therapy reduced mPAP by $3.97 \mathrm{mmHg}$ (95\% CI: $-6.06,-1.88 ; P<0.001)$ vs prostanoids, $8.24 \mathrm{mmHg}(95 \% \mathrm{CI}:-10.71,-5.76 ; P<0.001)$ vs ERAs, $3.38 \mathrm{mmHg}$ (95\% CI: $-6.30,-0.47 ; P=0.023)$ vs PDE-5Is, and $3.94 \mathrm{mmHg}(95 \% \mathrm{CI}:-6.99,-0.88 ; P=0.012)$ vs sGCS.

As shown in Figure 3B ( $\mathrm{n}=11$ studies), oral targeted drugs could decrease mPAP significantly more than placebo, with no significant heterogeneity found $(\tau \approx 0)$. Of note, oral prostanoids, oral ERAs, oral PDE-5Is, and sGCS had approximately comparable mPAP changes with each other. Combination therapy was associated with reduced $\mathrm{mPAP}$ by $11.45 \mathrm{mmHg}(95 \% \mathrm{CI}:-15.37,-7.53 ; P<0.001)$ vs prostanoids, $8.24 \mathrm{mmHg}(95 \% \mathrm{CI}:-10.69,-5.79 ; P<0.001)$ vs ERAs, $10.03 \mathrm{mmHg}(95 \% \mathrm{CI}:-14.10,-5.95 ; P<0.001)$ vs PDE-5Is, and $10.57 \mathrm{mmHg}$ (95\% CI: $-14.71,-6.42$; $P<0.001)$ vs sGCS.

In 16 studies, targeted drugs including prostanoids, ERAs, PDE-5Is, sGCS, and combination therapy were associated with more reduced PVR than placebo, with a consistency model used, regardless of the forms of drug administration ( $\tau=1.71$, $\chi^{2}=0.36, P=0.550$; Figure $3 \mathrm{C} ; \tau=1.01, \chi^{2}=3.17, P=0.075$; Figure 3D). Moreover, the mean values of the reduction in PVR were $\sim 14.7 \%, 9.8 \%, 19.2 \%, 28.2 \%$, and $22.4 \%$ for prostanoids, ERAs, PDE-5Is, sGCS, and combination therapy respectively ( mean $17.5 \%$ for single targeted drug), while the values of PVR were increased by $3.4 \%$ in terms of placebo. However, prostanoids, ERAs, PDE-5Is, sGCS, and combination therapy were comparable in reduced PVR with each other.

\section{All-cause mortality}

All-cause mortality was reported in 24 studies. There were no significant differences in all-cause mortality between prostanoids, ERAs, PDE-5Is, sGCS, combination therapy, and placebo (odds ratio [OR]: 0.59, 95\% CI: $0.34,1.03 ; P=0.063$ for prostanoids; OR: $0.65,95 \%$ CI: $0.29,1.46 ; P=0.295$ for ERAs; OR: $0.60,95 \%$ CI: 0.18, $1.97 ; P=0.397$ for PDE5Is; OR: $0.39,95 \%$ CI: $0.07,2.08 ; P=0.271$ for sGCS; OR: $0.54,95 \%$ CI: $0.17,1.74 ; P=0.301$ for combination therapy; 
A

6MWD of targeted drugs

ID

WMD $(95 \% \mathrm{Cl})$

Prostanoids vs placebo

ERAs vs placebo

PDE-5ls vs placebo

sGCS vs placebo

Combination vs placebo

ERAs vs prostanoids

PDE-5Is vs prostanoids

sGCS vs prostanoids

Combination vs prostanoids

PDE-5Is vs ERAs

sGCS vs ERAs

Combination vs ERAs

sGCS vs PDE-5Is

Combination vs PDE-5Is

Combination vs sGCS

Favors drug 2

Favors drug 1

$36.01(27.60,44.43)$

$40.01(31.47,48.55)$

$53.29(39.79,66.78)$

$36.50(12.62,60.38)$

$56.94(44.21,69.68)$

$4.00(-7.94,15.94)$

$17.28(1.91,32.65)$

$0.49(-24.82,25.80)$

$20.94(6.94,34.94)$

$13.29(-1.30,27.87)$

$-3.50(-28.86,21.86)$

$16.94(4.41,29.47)$

$-16.73(-44.14,10.68)$

$3.70(-11.15,18.55)$

$20.54(-6.43,47.51)$

B

ID

6MWD of oral targeted drugs

Prostanoids vs placebo

ERAs vs placebo

PDE-5ls vs placebo

sGCS vs placebo

Combination vs placebo

ERAs vs prostanoids

PDE-5ls vs prostanoids

sGCS vs prostanoids

Combination vs prostanoids

PDE-5Is vs ERAs

sGCS vs ERAs

Combination vs ERAs

sGCS vs PDE-5Is

Combination vs PDE-5Is

Combination vs sGCS

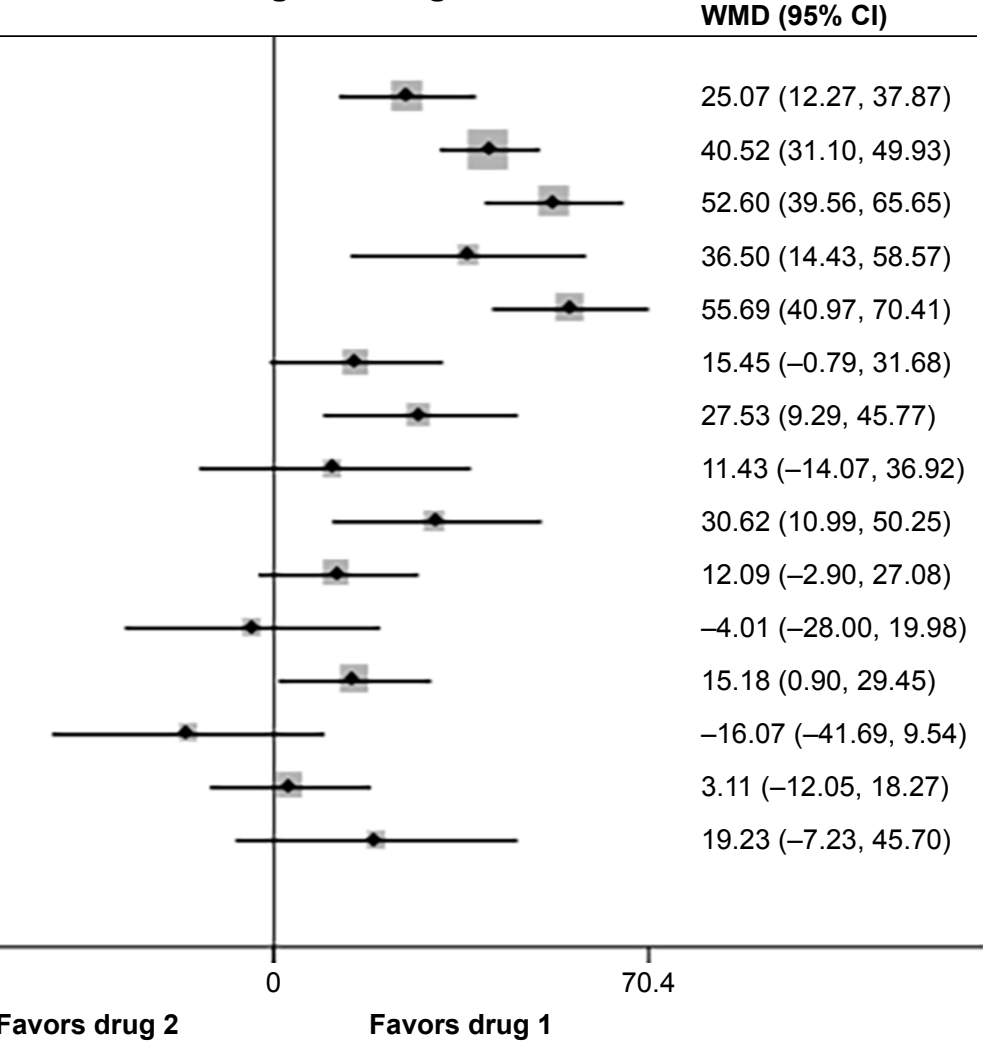

Figure 2 Pooled WMD and 95\% Cls determined by network meta-analysis for 6MWD of targeted drugs (A) or oral targeted drugs (B) for PAH.

Abbreviations: 6MWD, 6-minute walk distance; $\mathrm{Cl}$, confidence interval; ERAs, endothelin receptor antagonists; PAH, pulmonary arterial hypertension; PDE-5ls, phosphodiesterase 5 inhibitors; sGCS, soluble guanylate cyclase stimulator; WMD, weighted mean difference. 
A

mPAP of targeted drugs

ID

WMD $(95 \% \mathrm{Cl})$

Prostanoids vs placebo

ERAs vs placebo

PDE-5ls vs placebo

sGCS vs placebo

Combination vs placebo

ERAs vs prostanoids

PDE-5Is vs prostanoids

sGCS vs prostanoids

Combination vs prostanoids

PDE-5Is vs ERAs

sGCS vs ERAs

Combination vs ERAs

sGCS vs PDE-5Is

Combination vs PDE-5Is

Combination vs sGCS

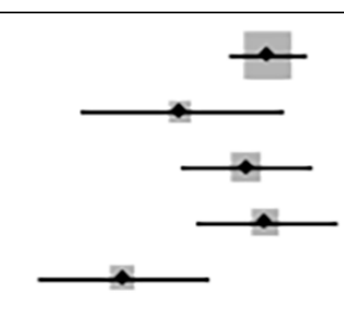

$-3.47(-4.54,-2.40)$

$-5.83(-8.63,-3.03)$

$-4.05(-5.86,-2.25)$

$-3.50(-5.44,-1.56)$

$-7.44(-9.80,-5.08)$

$4.27(1.03,7.51)$

$-0.58(-2.63,1.46)$

$-0.03(-2.24,2.18)$

$-3.97(-6.06,-1.88)$

$1.78(-1.55,5.10)$

$2.33(-1.08,5.73)$

$-8.24(-10.71,-5.76)$

$0.55(-2.09,3.20)$

$-3.38(-6.30,-0.47)$

$-3.94(-6.99,-0.88)$

\section{$-10.8$}

Favors drug 1

Favors drug 2

B

ID

mPAP of oral targeted drugs

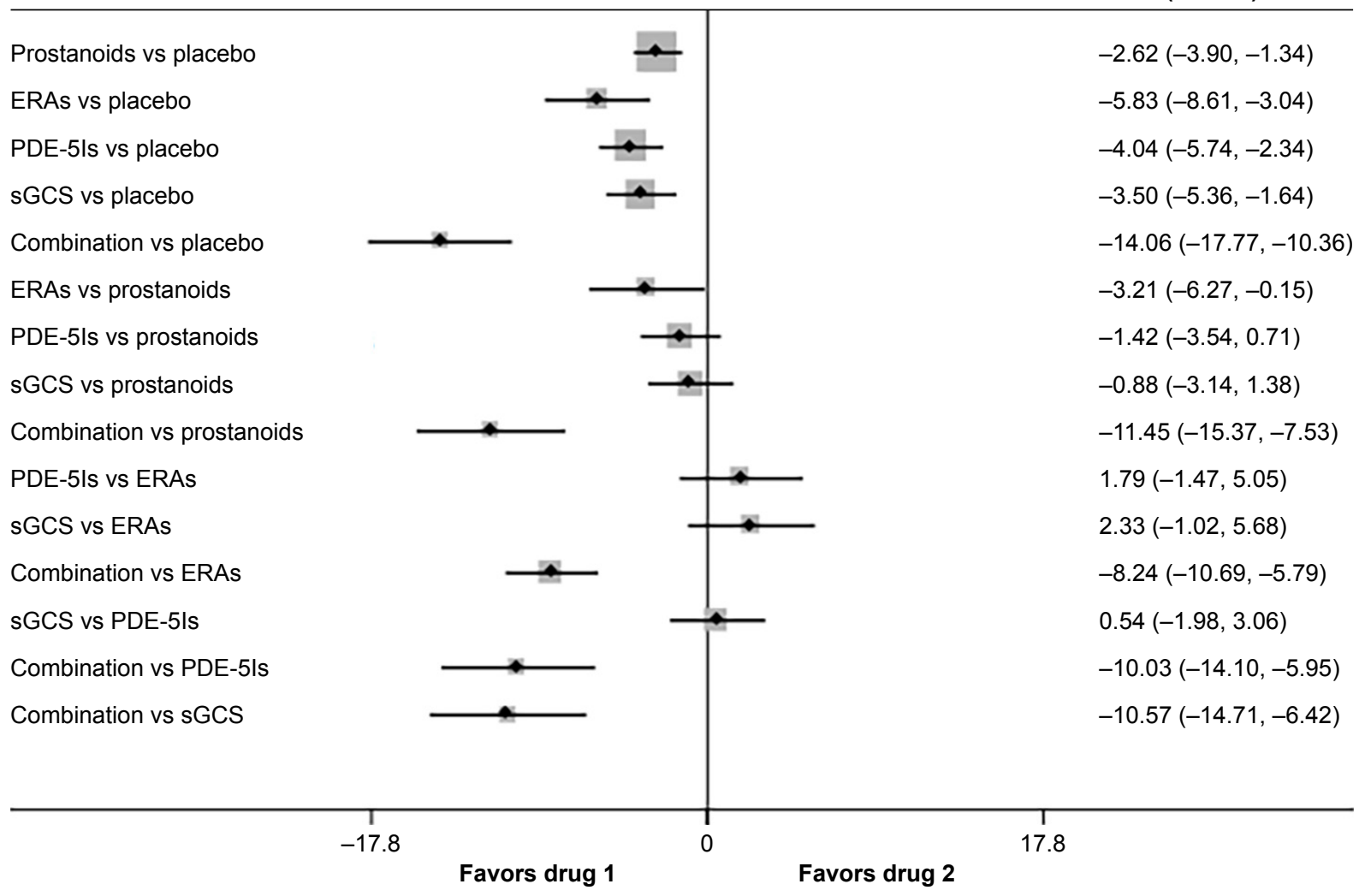

Figure 3 (Continued) 


\section{C}

\section{Study ID}

Prostanoids vs placebo

ERAs vs placebo

PDE-5Is vs placebo

sGCS vs placebo

Combination vs placebo

ERAs vs prostanoids

PDE-5ls vs prostanoids

sGCS vs prostanoids

Combination vs prostanoids

PDE-5Is vs ERAs

sGCS vs ERAs

Combination vs ERAs

sGCS vs PDE-5Is

Combination vs PDE-5ls

Combination vs sGCS
PVR of targeted drugs

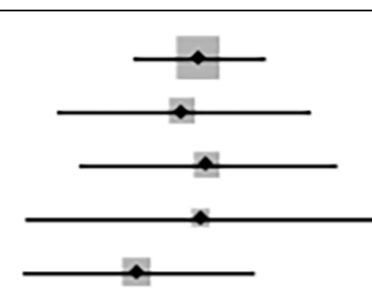

$-3.99(-5.33,-2.65)$

$-4.31(-6.88,-1.73)$

$-3.82(-6.43,-1.20)$

$-3.91(-7.52,-0.30)$

$-5.22(-7.57,-2.87)$

$-0.39(-2.98,2.19)$

$0.40(-2.48,3.28)$

$0.32(-3.44,4.08)$

$-1.52(-3.70,0.65)$

$0.80(-2.66,4.27)$

$0.72(-3.48,4.92)$

$-1.10(-3.23,1.04)$

$0.09(-4.03,4.21)$

$-1.64(-4.68,1.39)$

$-1.49(-4.92,1.93)$

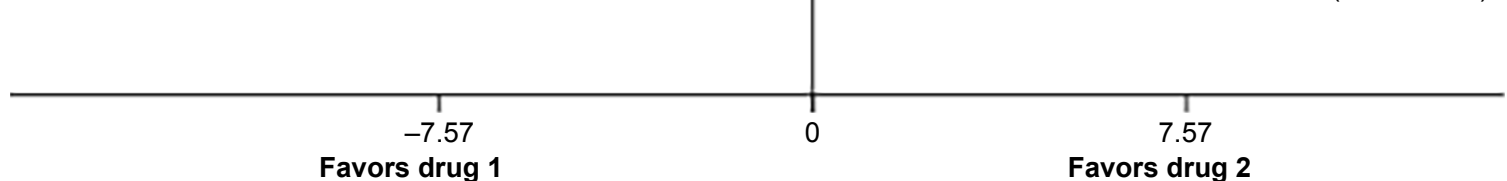

Favors drug 1

Favors drug 2

D

Study ID

PVR of oral targeted drugs

Prostanoids vs placebo

ERAs vs placebo

PDE-5ls vs placebo

sGCS vs placebo

Combination vs placebo

ERAs vs prostanoids

PDE-5Is vs prostanoids

sGCS vs prostanoids

Combination vs prostanoids

PDE-5Is vs ERAs

sGCS vs ERAs

Combination vs ERAs

sGCS vs PDE-5Is

Combination vs PDE-5ls

Combination vs sGCS

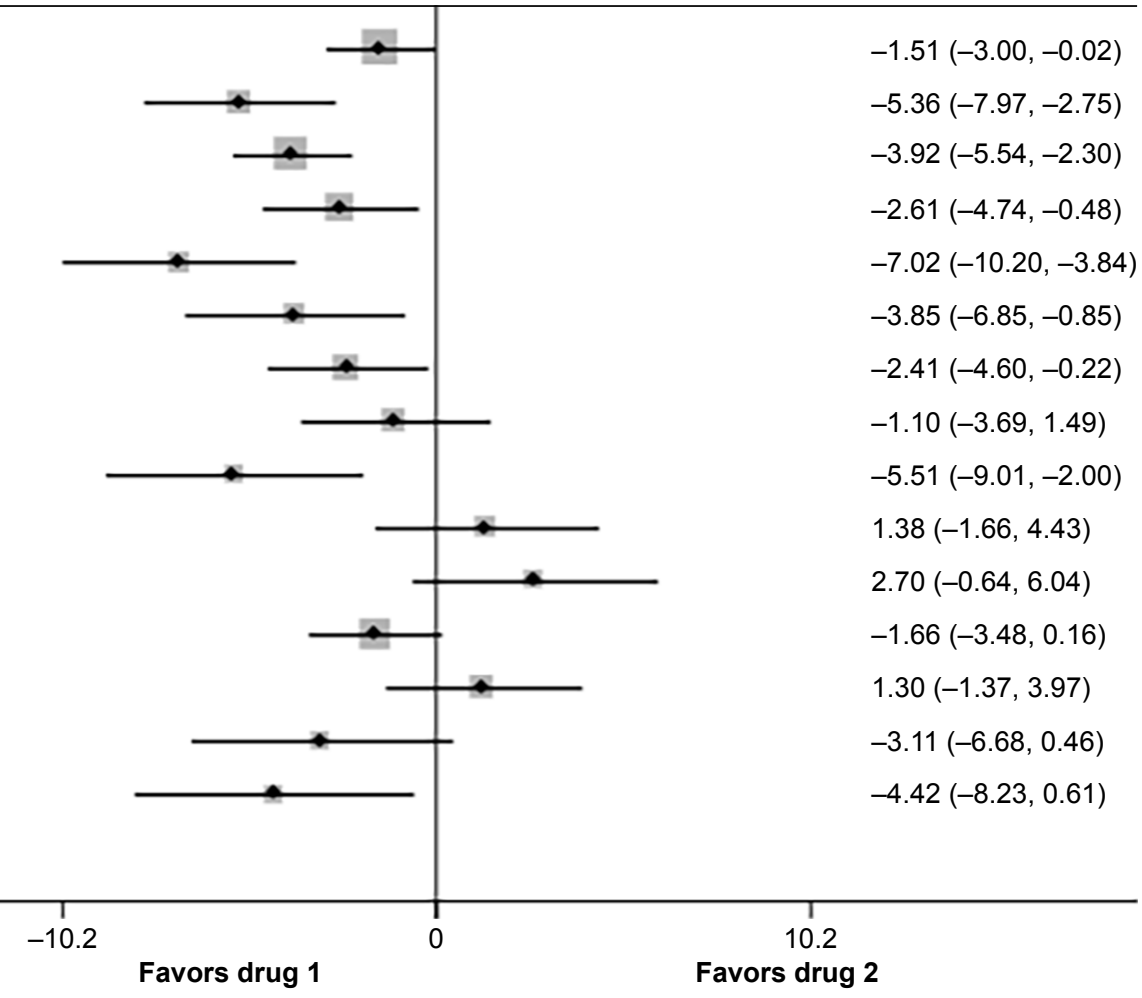

Figure 3 Pooled WMD and $95 \%$ Cls determined by network meta-analysis for mean pulmonary artery pressure of targeted drugs (A) or oral targeted drugs (B) for PAH. Pooled WMD and 95\% Cls determined by network meta-analysis for pulmonary vascular resistance of targeted drugs (C) or oral targeted drugs (D) for PAH.

Abbreviations: $\mathrm{Cl}$, confidence interval; ERAs, endothelin receptor antagonists; mPAP, mean pulmonary artery pressure; PAH, pulmonary arterial hypertension; PDE-5ls, phosphodiesterase 5 inhibitors; PVR, pulmonary vascular resistance; sGCS, soluble guanylate cyclase stimulator; WMD, weighted mean difference. 
respectively; Figure 4A), with a consistency model used $\left(\tau=0.21, \chi^{2}=4.69, P=0.320\right)$.

Among the 15 studies, oral prostanoids, oral ERAs, oral PDE-5Is, sGCS, and combination therapy could not decrease all-cause mortality more than placebo (OR: 0.76 , 95\% CI: $0.33,1.77 ; P=0.528$ for oral prostanoids; OR: 0.70 , 95\% CI: $0.30,1.64 ; P=0.415$ for oral ERAs; OR: $0.86,95 \%$ CI: $0.23,3.23 ; P=0.824$ for oral PDE-5Is; OR: $0.39,95 \% \mathrm{CI}$ : $0.08,2.01 ; P=0.262$ for sGCS; OR: $0.87,95 \%$ CI: $0.22,3.38$; $P=0.840$ for combination therapy, respectively; Figure 4B), with a consistency model used $\left(\tau=0.14, \chi^{2}=3.06, P=0.383\right)$.

\section{Clinical worsening events}

In 22 studies, there were significantly lower rates of clinical worsening events in prostanoids, ERAs, PDE-5Is, sGCS, and combination therapy than in placebo (Figure 5A), with a consistency model used ( $\tau=0.30, \chi^{2}=8.09, P=0.325$ ). However, prostanoids, ERAs, PDE-5Is, sGCS, and combination therapy were comparable in clinical worsening events with each other.

Oral ERAs, oral PDE-5Is, sGCS, and combination therapy were associated with reduced clinical worsening events than placebo, while oral prostanoids had similar events with placebo (18 studies, Figure 5B), with a consistency

A

Mortality of targeted drugs

ID

\section{Mortality of targeted drugs}

OR $(95 \% \mathrm{Cl})$

Prostanoids vs placebo

ERAs vs placebo

PDE-5ls vs placebo

sGCS vs placebo

Combination vs placebo

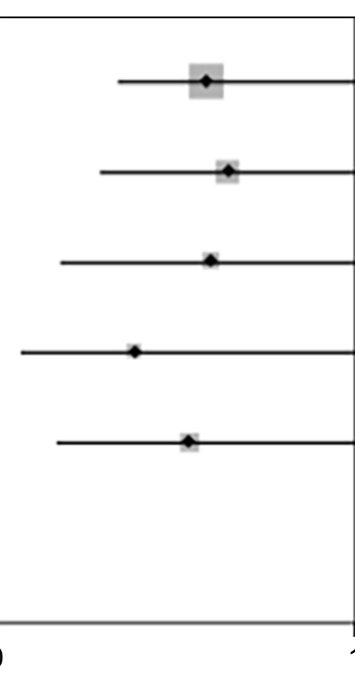

Favors drug 1
$0.59(0.34,1.03)$

$0.65(0.29,1.46)$

$0.60(0.18,1.97)$

$0.39(0.07,2.08)$

$0.54(0.17,1.74)$

OR $(95 \% \mathrm{Cl})$

$0.76(0.33,1.77)$

$0.70(0.30,1.64)$

$0.86(0.23,3.23)$

$0.39(0.08,2.01)$

$0.87(0.22,3.38)$

Combination vs placebo

Mortality of oral targeted drugs

ID

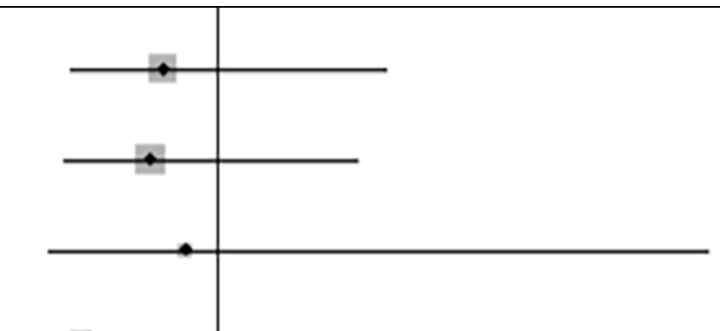

Prostanoids vs placebo

ERAs vs placebo

PDE-5ls vs placebo

sGCS vs placebo

Combination vs placebo

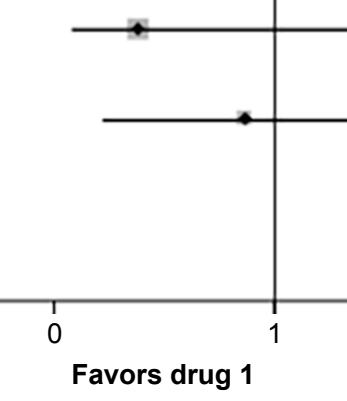

Favors drug 1

\begin{tabular}{llll}
\hline & & \\
\hline & Favors drug 1 & Favors drug 2 & 3.4
\end{tabular}

Figure 4 Pooled OR and $95 \%$ Cls determined by network meta-analysis for all-cause mortality of targeted drugs (A) or oral targeted drugs (B) for PAH.

Abbreviations: $\mathrm{Cl}$, confidence interval; ERAs, endothelin receptor antagonists; OR, odds ratio; PAH, pulmonary arterial hypertension; PDE-5ls, phosphodiesterase 5 inhibitors; sGCS, soluble guanylate cyclase stimulator. 
A

ID

Clinical worsening of targeted drugs

Prostanoids vs placebo

ERAs vs placebo

PDE-5ls vs placebo

sGCS vs placebo

Combination vs placebo

ERAs vs prostanoids

PDE-5Is vs prostanoids

sGCS vs prostanoids

Combination vs prostanoids

PDE-5Is vs ERAs

sGCS vs ERAs

Combination vs ERAs

sGCS vs PDE-5ls

Combination vs PDE-5Is

Combination vs sGCS

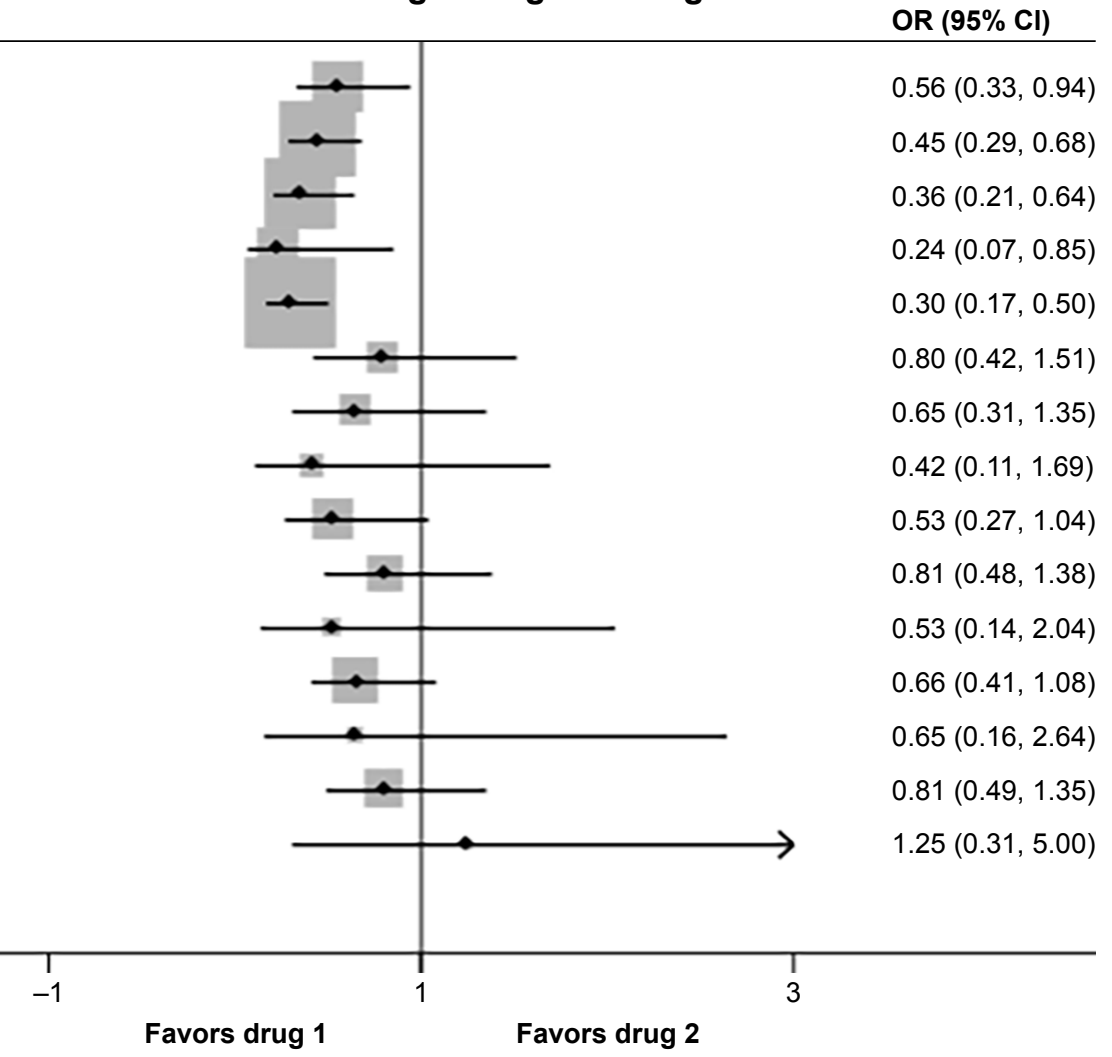

B

Clinical worsening of oral targeted drugs

ID

OR (95\% Cl)

Prostanoids vs placebo

ERAs vs placebo

PDE-5Is vs placebo

sGCS vs placebo

Combination vs placebo

ERAs vs prostanoids

PDE-5Is vs prostanoids

sGCS vs prostanoids

Combination vs prostanoids

PDE-5Is vs ERAs

sGCS vs ERAs

Combination vs ERAs

sGCS vs PDE-5Is

Combination vs PDE-5ls

Combination vs sGCS

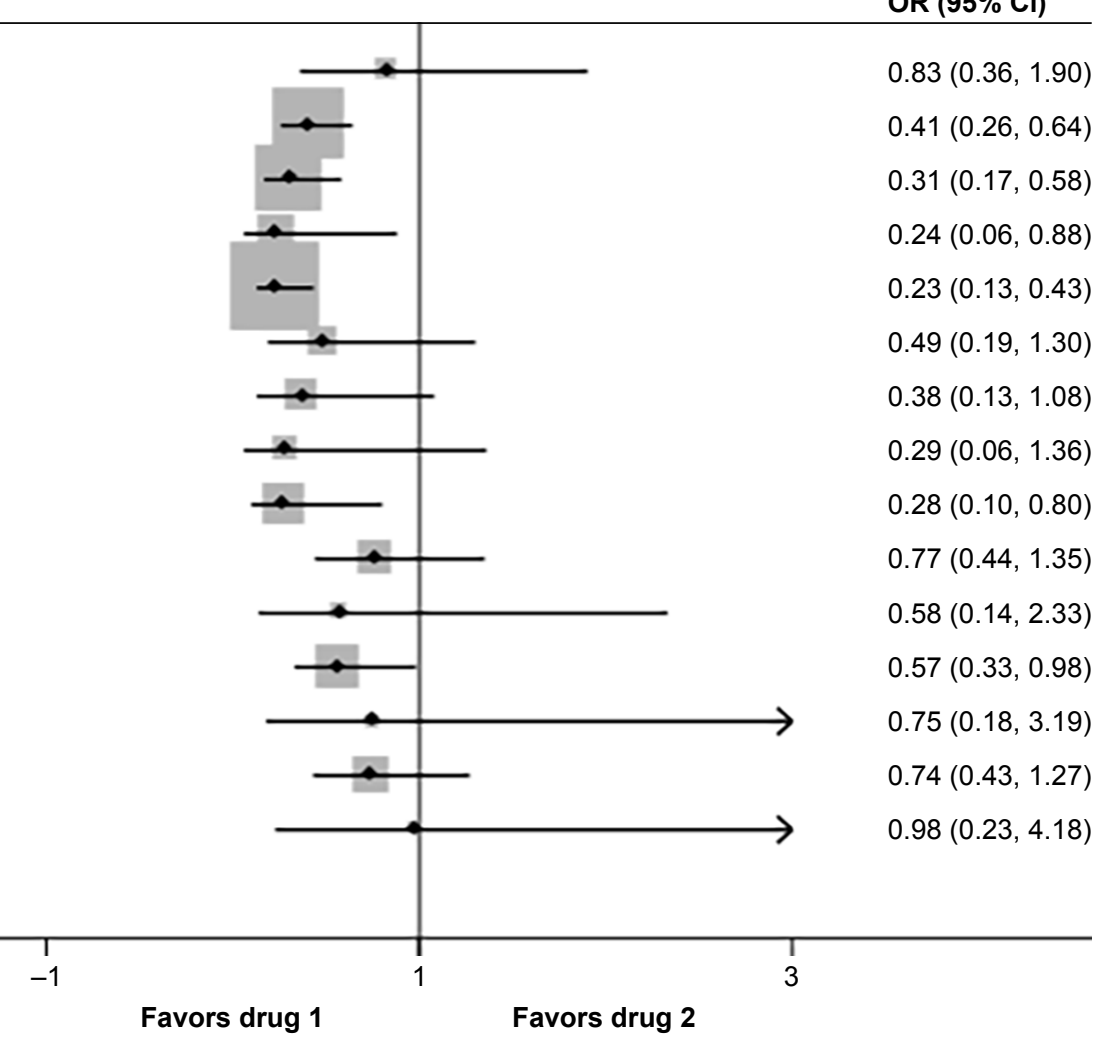

Figure 5 Pooled OR and 95\% Cls determined by network meta-analysis for clinical worsening events of targeted drugs (A) or oral targeted drugs (B) for PAH. Abbreviations: $\mathrm{Cl}$, confidence interval; ERAs, endothelin receptor antagonists; OR, odds ratio; PAH, pulmonary arterial hypertension; PDE-5ls, phosphodiesterase 5 inhibitors; sGCS, soluble guanylate cyclase stimulator. 
model used $\left(\tau=0.33, \chi^{2}=4.87, P=0.561\right)$. Oral prostanoids, oral ERAs, oral PDE-5Is, and sGCS were comparable with each other. Moreover, combination therapy improved clinical worsening events more than oral prostanoids (OR: 0.28, 95\% CI: 0.10, 0.80; $P=0.017$ ) and oral ERAs (OR: 0.57, 95\% CI: 0.33, 0.98; $P=0.044)$.

\section{SAEs}

A total of 19 studies evaluated the safety of targeted drugs by assessing the SAEs. The incidences of SAEs were similar, and the differences were not statistically significant between targeted drugs and placebo, with a consistency model used, regardless of the forms of drug administration $(\tau=0.07$, $\chi^{2}=1.29, P=0.863$; Figure $6 \mathrm{~A} ; \tau \approx 0, \chi^{2}=0.63, P=0.889$; Figure 6B).

\section{Discussion}

To the best of our best knowledge, this was the first network meta-analysis comparing the efficacy of different targeted drugs of PAH. The major findings of the present metaanalysis were as follows: 1) prostanoids, ERAs, PDE-5Is, sGCS, and combination therapy could improve 6MWD,

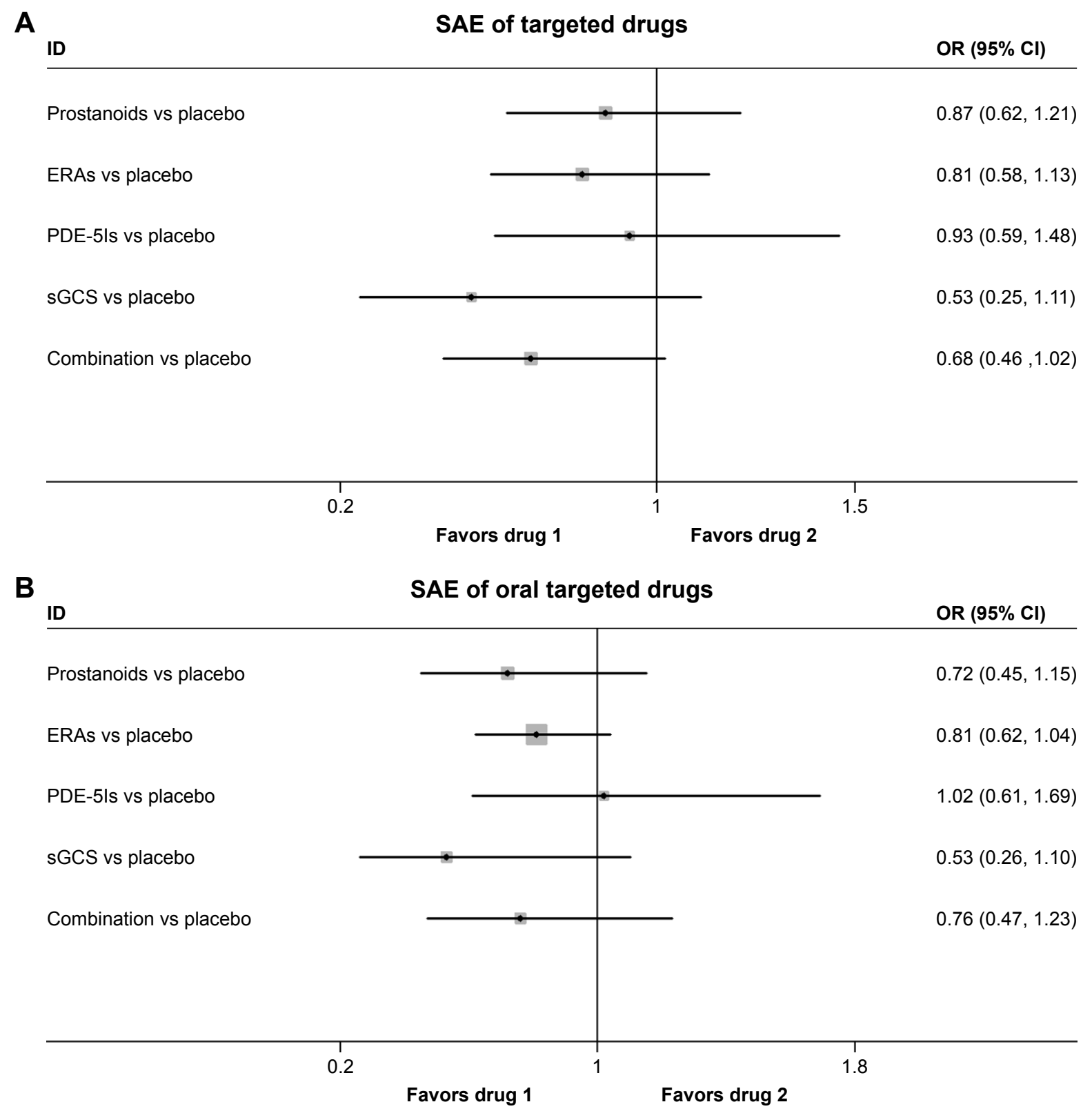

Figure 6 Pooled OR and 95\% Cls determined by network meta-analysis for SAEs of targeted drugs (A) or oral targeted drugs (B) for PAH.

Abbreviations: $\mathrm{Cl}$, confidence interval; ERAs, endothelin receptor antagonists; OR, odds ratio; PAH, pulmonary arterial hypertension; PDE-5Is, phosphodiesterase 5 inhibitors; SAE, serious adverse event; sGCS, soluble guanylate cyclase stimulator. 
mPAP, PVR, and clinical worsening events for patients with PAH, regardless of drug dosage forms; 2) nonoral targeted drugs for PAH patients, including intravenous, inhaled, and subcutaneous forms, were superior to their oral forms; 3) none of the targeted drugs could significantly reduce the risk of all-cause mortality of PAH patients; 4) PDE-5Is might be more superior to prostanoids in increasing 6MWD (primary end point), with a similar result with combination therapy; and 5) $\mathrm{PAH}$ patients might benefit mostly from the combination therapy and modestly from prostanoids.

PAH is a hemodynamic and pathophysiologic state, characterized by a progressive increase in pulmonary vascular resistance and loss of pulmonary arterial compliance, which is associated with dyspnea, decreased exercise tolerance, and right heart failure. ${ }^{1}$ According to the classification of WHO, PAH could be idiopathic, heritable, or associated with connective tissue disease, congenital heart disease, portal hypertension, and others. ${ }^{45}$ The pathophysiology of PAH is complex, but it involves vasoconstriction and/or vasodilation imbalance, thrombosis, cell proliferation, and remodeling of the pulmonary arterial walls, particularly the molecular mechanisms of endothelial dysfunction factors including nitric oxide, prostacyclin, and endothelin. ${ }^{46}$ Treatment options for PAH have developed rapidly, due to the increasing knowledge of the pathophysiology of this disease, mainly including supportive therapy, psychosocial support, and targeted drug therapy. Classical compounds of targeted drugs cover prostacyclin analogs, ERAs, PDE-5Is, and sGCS. The importance of distinguishing PAH from the other types of pulmonary hypertension is that these specific drugs target the molecular pathways of $\mathrm{PAH}$, which might not be effective in the other forms of pulmonary hypertension. For this reason, these targeted drugs in treating non-PAH pulmonary hypertension are not supported, ${ }^{47}$ except for riociguat (sGCS), which is also approved for patients with chronic thromboembolic pulmonary hypertension. Furthermore, many $\operatorname{RCTs}^{9-11,31}$ and meta-analyses ${ }^{12-14}$ have demonstrated that these four types of targeted drugs has been shown to improve hemodynamics, exercise capacity, and possible survival. However, which drug or therapy regimen could provide the best efficacy for PAH patients in these four targeted drugs and their combination therapies remains unanswered. So far, direct head-to-head comparisons of targeted drugs are lacking, and traditional meta-analyses do not allow adequate assessment of the comparative effectiveness of all therapy regimens. Therefore, a comprehensive network meta-analysis enrolling as many relevant studies as possible is warranted to guide clinical practice in the real world.
In the present network meta-analysis, we confirmed that all targeted drugs could improve 6MWD and hemodynamics compared to placebo, in accordance with previous studies, ${ }^{13,14}$ but there was no significant decreased risk of mortality found in these active treatments. Similarly, the meta-analysis by Zhang et $\mathrm{al}^{14}$ and Lajoie et $\mathrm{al}^{48}$ concluded that oral targeted drugs, and even combination therapy, were associated with no sufficient efficacy on survival in the short-term follow-up. Although another meta-analysis by Galiè et $\mathrm{al}^{49}$ showed significant reduction in mortality in $\mathrm{PAH}$ patients with the targeted drugs, only one study by Brast et al with epoprostenol ${ }^{21}$ provided favorable data in the total of 23 RCTs analyzed. Of note, none of the current studies of targeted drugs were designed to evaluate the mortality of PAH, and most studies showed no survival benefit, which might due to the small sample size and relative short duration. In addition, all studies included safety margins for patients on placebo, who were allowed to switch to active drug or other medications in case of deterioration. Future clinical trials, setting mortality as the primary end point with enough power, should be designed to clarify the real survival value of targeted drugs. Furthermore, we found that combination therapy improved 6MWD and reduced the risk of clinical worsening in $\mathrm{PAH}$ patients compared with monotherapy, especially prostanoids. The results were also consistent with previous studies. ${ }^{50,51}$ Overall, we concluded that monotargeted drugs and their combination regimens could improve multiple clinical and hemodynamic outcomes, but they might have no effect on mortality.

Several questions remain unanswered. First, we found none of clinical trials assessing mortality as a primary end point. Surrogate end points, including 6MWD, hemodynamics, and clinical worsening events, have played a critical role in PAH clinical trials because of disease rarity, small population, participant burden, cost, and short follow-up time. ${ }^{52}$ However, it is still unclear whether these surrogate end points could represent the true response to targeted drugs for PAH patients. Second, many agents approved for PAH are always delivered in pill form, for stability and a convenient administration route. Although oral targeted drugs have an important position in the PAH management, they have several limitations and drawbacks, especially in patients in WHO IV category and with severe right heart failure. According to our study, non-oral-targeted drugs, including intravenous, inhaled, and subcutaneous drugs, have improved efficacy compared to oral forms. Third, numerous RCTs and meta-analyses have suggested that sequential combination therapy is effective, meanwhile the recent AMBITION (Ambrisentan and Tadalafil in Patients with Pulmonary 
Arterial Hypertension) study showed upfront treatment with tadalafil and ambrisentan was superior to monotherapy. ${ }^{30}$ Nevertheless, it is still unclear whether upfront combination therapy improves clinical outcomes compared with sequential add-on therapy in cases of unsatisfactory response to initial monotherapy, which is recommended by the guidelines. ${ }^{1,5}$ In addition, various treatment options, apart from targeted drugs, are also available for PAH, including atrial septostomy, pulmonary transplantation, and pulmonary artery denervation (PADN). PADN from single-center studies has been demonstrated to be safe and effective in improving 6MWD and hemodynamics and in reducing PAH-related events and death throughout the 1-year follow-up. ${ }^{53,54}$ Further multicenter RCTs are required to confirm the efficacy of PADN and to explore whether PADN could replace the targeted drugs, given the expensive fee and unclear long-term effect.

\section{Limitations}

There are several limitations in the present study. First, different studies used different clinical worsening events definition, which might be an important source of bias. Second, lack of other potential confounding factors, such as etiology of $\mathrm{PAH}$, WHO function, background treatment, and withdrawal due to adverse effects, did not allow us to investigate the detailed impact of targeted drugs on clinical end points and the underlying mechanisms. Third, there was no publication bias evaluation in the present study, which did not affect the interpretation of the results. Fourth, the study about selexipag, a novel prostacyclin receptor agonist, was excluded in present meta-analysis, just because the publication date of GRIPHON study ${ }^{55}$ was later than the predetermined time period in our protocol. Furthermore, there was not enough data about PAH-related SAEs and treatment-related SAEs in most of the enrolled studies. As a result, we could not evaluate the SAEs caused by targeted drugs. Finally, the follow-up period in all enrolled studies was relatively different for comparison of targeted drugs.

\section{Conclusion}

In conclusion, this network meta-analysis suggests that all targeted drugs for PAH are associated with improved clinical outcomes, especially combination therapy. However, all these drugs seem to show less favorable effects on survival in the short-term follow-up, suggesting further clinical trials are required.

\section{Acknowledgment}

The study is supported by the Jiangsu Provincial Special Program of Medical Science (BL2013001).

\section{Author contributions}

CSL had the original idea and designed the study. GXF and ZJJ performed the systematic literature search, study identification, data extraction, and quality assessment. JXM and GZ undertook the statistical analysis. WZM, LB, and MWX drafted the article. All authors revised and approved the final report. All authors contributed toward data analysis, drafting and critically revising the paper and agree to be accountable for all aspects of the work.

\section{Disclosure}

The authors report no conflicts of interest in this work.

\section{References}

1. Galie N, Hoeper MM, Humbert M, et al. Guidelines for the diagnosis and treatment of pulmonary hypertension: the Task Force for the Diagnosis and Treatment of Pulmonary Hypertension of the European Society of Cardiology (ESC) and the European Respiratory Society (ERS), endorsed by the International Society of Heart and Lung Transplantation (ISHLT). Eur Heart J. 2009;30:2493-2537.

2. Wilkins MR, Paul GA, Strange JW, et al. Sildenafil versus Endothelin Receptor Antagonist for Pulmonary Hypertension (SERAPH) study. Am J Respir Crit Care Med. 2005;171:1292-1297.

3. Benza RL, Miller DP, Barst RJ, Badesch DB, Frost AE, McGoon MD. An evaluation of long-term survival from time of diagnosis in pulmonary arterial hypertension from the REVEAL Registry. Chest. 2012; 142:448-456.

4. NazzarenoGaliè MH, Vachiery JL, Gibbs S. 2015 ESC/ERS Guidelines for the diagnosis and treatment of pulmonary hypertension. The Joint Task Force for the Diagnosis and Treatment of Pulmonary Hypertension of the European Society of Cardiology (ESC) and the European Respiratory Society (ERS). Eur Respir J. 2015;46:1855-1856.

5. McLaughlin VV, Shah SJ, Souza R, Humbert M. Management of pulmonary arterial hypertension. J Am Coll Cardiol. 2015;65:1976-1997.

6. Olschewski H, Simonneau G, Galie N, et al. Inhaled iloprost for severe pulmonary hypertension. $N$ Engl J Med. 2002;347:322-329.

7. McLaughlin VV, Gaine SP, Barst RJ, et al. Efficacy and safety of treprostinil: an epoprostenol analog for primary pulmonary hypertension. J Cardiovasc Pharmacol. 2003;41:293-299.

8. Rubin LJ, Badesch DB, Barst RJ, et al. Bosentan therapy for pulmonary arterial hypertension. N Engl J Med. 2002;346:896-903.

9. Galie N, Ghofrani HA, Torbicki A, et al. Sildenafil citrate therapy for pulmonary arterial hypertension. $N$ Engl J Med. 2005;353:2148-2157.

10. Ghofrani HA, Galie N, Grimminger F, et al. Riociguat for the treatment of pulmonary arterial hypertension. N Engl J Med. 2013;369: 330-340.

11. Pulido T, Adzerikho I, Channick RN, et al. Macitentan and morbidity and mortality in pulmonary arterial hypertension. $N$ Engl J Med. 2013; 369:809-818.

12. Coeytaux RR, Schmit KM, Kraft BD, et al. Comparative effectiveness and safety of drug therapy for pulmonary arterial hypertension: a systematic review and meta-analysis. Chest. 2014;145:1055-1063.

13. Zheng YG, Ma H, Hu EC, Liu G, Chen G, Xiong CM. Oral targeted therapies in the treatment of pulmonary arterial hypertension: a meta-analysis of clinical trials. Pulm Pharmacol Ther. 2014;29: 241-249.

14. Zhang HD, Zhang R, Jiang X, Sun K, Wu DC, Jing ZC. Effects of oral treatments on clinical outcomes in pulmonary arterial hypertension: a systematic review and meta-analysis. Am Heart J. 2015;170: 96-103, 103.e1-e14.

15. Jadad AR, Moore RA, Carroll D, et al. Assessing the quality of reports of randomized clinical trials: is blinding necessary? Control Clin Trials. 1996;17:1-12. 
16. Chaimani A, Higgins JP, Mavridis D, Spyridonos P, Salanti G. Graphical tools for network meta-analysis in STATA. PLoS One. 2013;8:e76654.

17. White IR, Barrett JK, Jackson D, Higgins JP. Consistency and inconsistency in network meta-analysis: model estimation using multivariate meta-regression. Res Synth Methods. 2012;3:111-125.

18. Dias S, Welton NJ, Caldwell DM, Ades AE. Checking consistency in mixed treatment comparison meta-analysis. Stat Med. 2010;29: 932-944.

19. Higgins JP, Jackson D, Barrett JK, Lu G, Ades AE, White IR. Consistency and inconsistency in network meta-analysis: concepts and models for multi-arm studies. Res Synth Methods. 2012;3:98-110.

20. Rubin LJ, Mendoza J, Hood M, et al. Treatment of primary pulmonary hypertension with continuous intravenous prostacyclin (epoprostenol). Results of a randomized trial. Ann Intern Med. 1990;112:485-491.

21. Barst RJ, Rubin LJ, Long WA, et al. A comparison of continuous intravenous epoprostenol (prostacyclin) with conventional therapy for primary pulmonary hypertension. $N$ Engl J Med. 1996;334: 296-301.

22. Badesch DB, Tapson VF, McGoon MD, et al. Continuous intravenous epoprostenol for pulmonary hypertension due to the scleroderma spectrum of disease. A randomized, controlled trial. Ann Intern Med. 2000;132:425-434.

23. Channick RN, Simonneau G, Sitbon O, et al. Effects of the dual endothelin-receptor antagonist bosentan in patients with pulmonary hypertension: a randomised placebo-controlled study. Lancet. 2001; 358:1119-1123.

24. Galie N, Humbert M, Vachiery JL, et al. Effects of beraprost sodium, an oral prostacyclin analogue, in patients with pulmonary arterial hypertension: a randomized, double-blind, placebo-controlled trial. J Am Coll Cardiol. 2002;39:1496-1502.

25. Simonneau G, Barst RJ, Galie N, et al. Continuous subcutaneous infusion of treprostinil, a prostacyclin analogue, in patients with pulmonary arterial hypertension: a double-blind, randomized, placebocontrolled trial. Am J Respir Crit Care Med. 2002;165:800-804.

26. Barst RJ, McGoon M, McLaughlin V, et al. Beraprost therapy for pulmonary arterial hypertension. J Am Coll Cardiol. 2003;41:2119-2125.

27. Humbert M, Barst RJ, Robbins IM, et al. Combination of bosentan with epoprostenol in pulmonary arterial hypertension: BREATHE-2. Eur Respir J. 2004;24:353-359.

28. Hoeper MM, Leuchte H, Halank M, et al. Combining inhaled iloprost with bosentan in patients with idiopathic pulmonary arterial hypertension. Eur Respir J. 2006;28:691-694.

29. Barst RJ, Oudiz RJ, Beardsworth A, et al. Tadalafil monotherapy and as add-on to background bosentan in patients with pulmonary arterial hypertension. J Heart Lung Transplant. 2011;30:632-643.

30. Galie N, Barbera JA, Frost AE, et al. Initial use of ambrisentan plus tadalafil in pulmonary arterial hypertension. $N$ Engl J Med. 2015;373: 834-844.

31. Galie N, Beghetti M, Gatzoulis MA, et al. Bosentan therapy in patients with Eisenmenger syndrome: a multicenter, double-blind, randomized, placebo-controlled study. Circulation. 2006;114:48-54.

32. Galie N, Muller K, Scalise AV, Grunig E. PATENT PLUS: a blinded, randomised and extension study of riociguat plus sildenafil in pulmonary arterial hypertension. Eur Respir J. 2015;45:1314-1322.

33. Galie N, Olschewski H, Oudiz RJ, et al. Ambrisentan for the treatment of pulmonary arterial hypertension: results of the ambrisentan in pulmonary arterial hypertension, randomized, double-blind, placebocontrolled, multicenter, efficacy (ARIES) study 1 and 2. Circulation. 2008;117:3010-3019.

34. Galie N, Rubin L, Hoeper M, et al. Treatment of patients with mildly symptomatic pulmonary arterial hypertension with bosentan (EARLY study): a double-blind, randomised controlled trial. Lancet. 2008;371:2093-2100.

35. Hiremath J, Thanikachalam S, Parikh K, et al. Exercise improvement and plasma biomarker changes with intravenous treprostinil therapy for pulmonary arterial hypertension: a placebo-controlled trial. J Heart Lung Transplant. 2010;29:137-149.
36. Jing ZC, Parikh K, Pulido T, et al. Efficacy and safety of oral treprostinil monotherapy for the treatment of pulmonary arterial hypertension: a randomized, controlled trial. Circulation. 2013;127:624-633.

37. Jing ZC, Yu ZX, Shen JY, et al. Vardenafil in pulmonary arterial hypertension: a randomized, double-blind, placebo-controlled study. Am J Respir Crit Care Med. 2011;183:1723-1729.

38. McLaughlin V, Channick RN, Ghofrani HA, et al. Bosentan added to sildenafil therapy in patients with pulmonary arterial hypertension. Eur Respir J. 2015;46:405-413.

39. McLaughlin VV, Benza RL, Rubin LJ, et al. Addition of inhaled treprostinil to oral therapy for pulmonary arterial hypertension: a randomized controlled clinical trial. J Am Coll Cardiol. 2010;55:1915-1922.

40. McLaughlin VV, Oudiz RJ, Frost A, et al. Randomized study of adding inhaled iloprost to existing bosentan in pulmonary arterial hypertension. Am J Respir Crit Care Med. 2006;174:1257-1263.

41. Simonneau G, Rubin LJ, Galie N, et al. Addition of sildenafil to longterm intravenous epoprostenol therapy in patients with pulmonary arterial hypertension: a randomized trial. Ann Intern Med. 2008;149: $521-530$.

42. Tapson VF, Jing ZC, Xu KF, et al. Oral treprostinil for the treatment of pulmonary arterial hypertension in patients receiving background endothelin receptor antagonist and phosphodiesterase type 5 inhibitor therapy (the FREEDOM-C2 study): a randomized controlled trial. Chest. 2013;144:952-958.

43. Tapson VF, Torres F, Kermeen F, et al. Oral treprostinil for the treatment of pulmonary arterial hypertension in patients on background endothelin receptor antagonist and/or phosphodiesterase type 5 inhibitor therapy (the FREEDOM-C study): a randomized controlled trial. Chest. 2012;142:1383-1390.

44. Zhuang Y, Jiang B, Gao H, Zhao W. Randomized study of adding tadalafil to existing ambrisentan in pulmonary arterial hypertension. Hypertens Res. 2014;37:507-512.

45. Simonneau G, Gatzoulis MA, Adatia I, et al. Updated clinical classification of pulmonary hypertension. $J$ Am Coll Cardiol. 2013;62:D34-D41.

46. Tuder RM, Archer SL, Dorfmuller P, et al. Relevant issues in the pathology and pathobiology of pulmonary hypertension. $\mathrm{J} \mathrm{Am} \mathrm{Coll} \mathrm{Cardiol}$. 2013;62:D4-D12.

47. Taichman DB, Ornelas J, Chung L, et al. Pharmacologic therapy for pulmonary arterial hypertension in adults: CHEST guideline and expert panel report. Chest. 2014;146:449-475.

48. Lajoie AC, Lauziere G, Lega JC, et al. Combination therapy versus monotherapy for pulmonary arterial hypertension: a meta-analysis. Lancet Respir Med. 2016;4:291-305.

49. Galie N, Manes A, Negro L, Palazzini M, Bacchi-Reggiani ML, Branzi A. A meta-analysis of randomized controlled trials in pulmonary arterial hypertension. Eur Heart J. 2009;30:394-403.

50. Zhu B, Wang L, Sun L, Cao R. Combination therapy improves exercise capacity and reduces risk of clinical worsening in patients with pulmonary arterial hypertension: a meta-analysis. J Cardiovasc Pharmacol. 2012;60:342-346.

51. Bai Y, Sun L, Hu S, Wei Y. Combination therapy in pulmonary arterial hypertension: a meta-analysis. Cardiology. 2011;120:157-165.

52. Parikh KS, Rajagopal S, Arges K, et al. Use of outcome measures in pulmonary hypertension clinical trials. Am Heart J. 2015;170: 419-429.e3.

53. Chen SL, Zhang FF, Xu J, et al. Pulmonary artery denervation to treat pulmonary arterial hypertension: the single-center, prospective, firstin-man PADN-1 study (first-in-man pulmonary artery denervation for treatment of pulmonary artery hypertension). J Am Coll Cardiol. 2013;62:1092-1100.

54. Chen SL, Zhang H, Xie DJ, et al. Hemodynamic, functional, and clinical responses to pulmonary artery denervation in patients with pulmonary arterial hypertension of different causes: phase II results from the Pulmonary Artery Denervation-1 study. Circ Cardiovasc Interv. 2015;8:e02837.

55. Sitbon O, Channick R, Chin KM, et al. Selexipag for the Treatment of Pulmonary Arterial Hypertension. N Engl J Med. 2015;373(26): 2522-2533. 


\section{Supplementary materials}

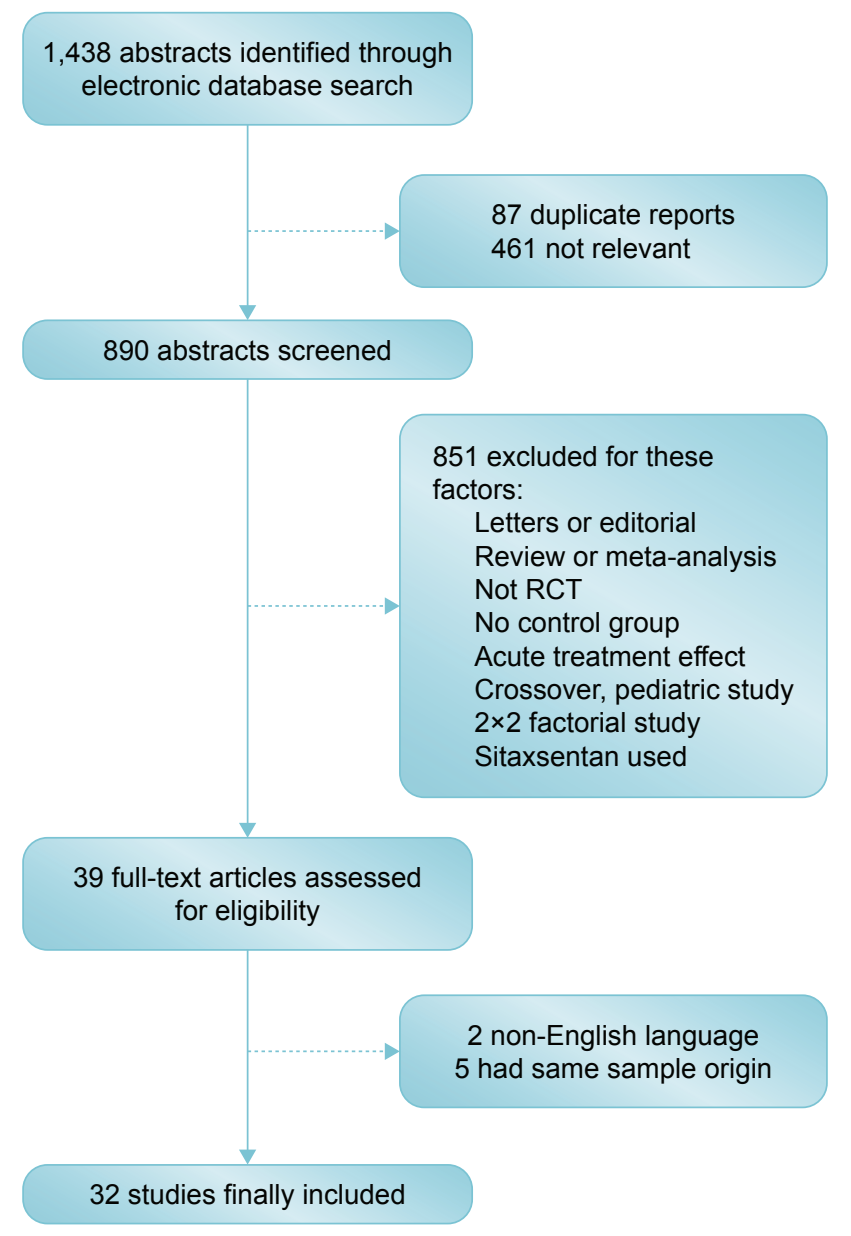

Figure SI Study selection flow chart.

Abbreviation: RCT, randomized controlled trial. 


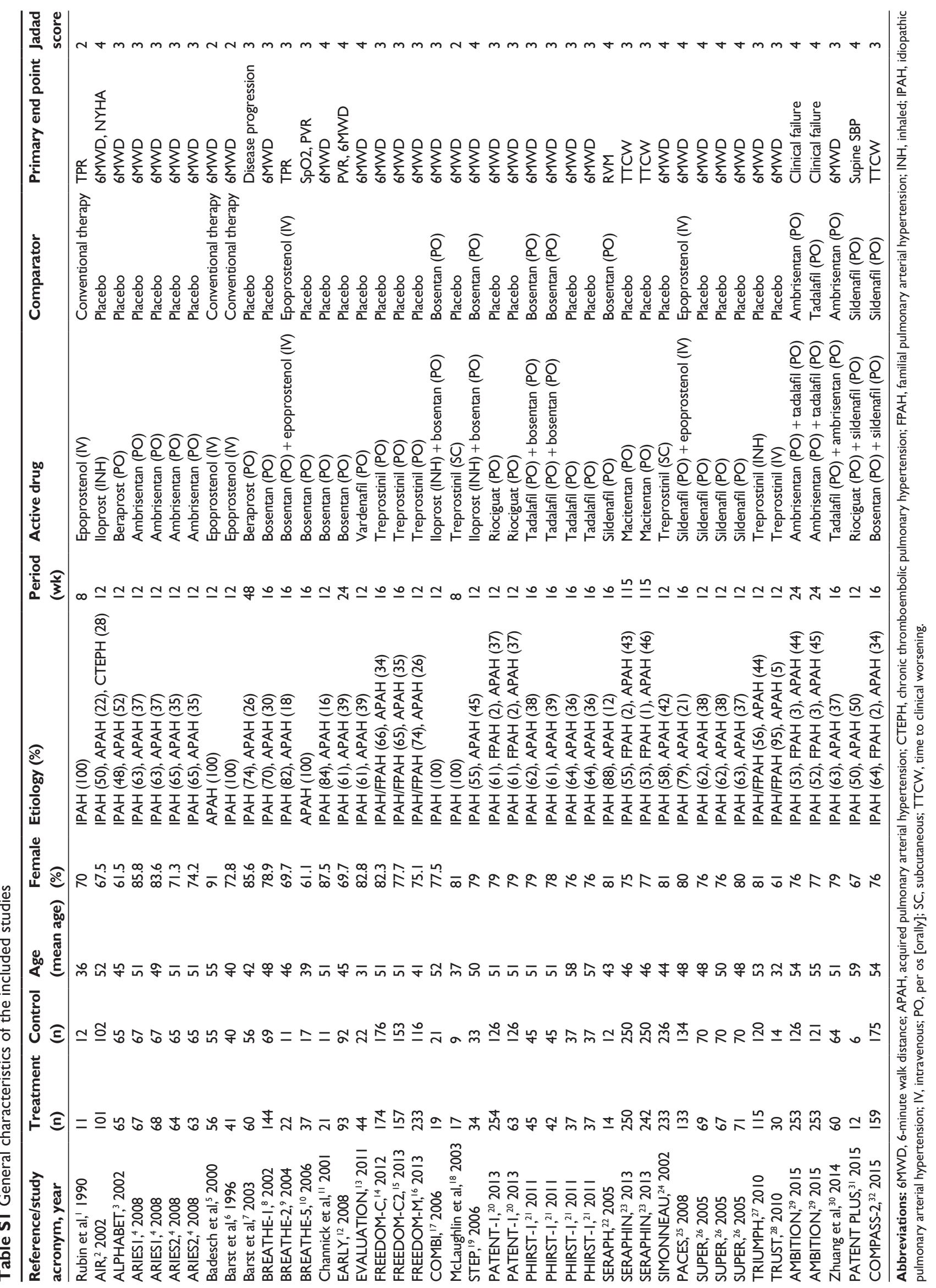




\section{References}

1. Rubin LJ, Mendoza J, Hood M, et al. Treatment of primary pulmonary hypertension with continuous intravenous prostacyclin (epoprostenol). Results of a randomized trial. Ann Intern Med. 1990;112:485-491.

2. Olschewski H, Simonneau G, Galie N, et al. Inhaled iloprost for severe pulmonary hypertension. $N$ Engl J Med. 2002;347:322-329.

3. Galie N, Humbert M, Vachiery JL, et al. Effects of beraprost sodium, an oral prostacyclin analogue, in patients with pulmonary arterial hypertension: a randomized, double-blind, placebo-controlled trial. J Am Coll Cardiol. 2002;39:1496-1502.

4. Galie N, Olschewski H, Oudiz RJ, et al. Ambrisentan for the treatment of pulmonary arterial hypertension: results of the ambrisentan in pulmonary arterial hypertension, randomized, double-blind, placebocontrolled, multicenter, efficacy (ARIES) study 1 and 2. Circulation. 2008;117:3010-3019.

5. Badesch DB, Tapson VF, McGoon MD, et al. Continuous intravenous epoprostenol for pulmonary hypertension due to the scleroderma spectrum of disease. A randomized, controlled trial. Ann Intern Med. 2000;132:425-434.

6. Barst RJ, Rubin LJ, Long WA, et al. A comparison of continuous intravenous epoprostenol (prostacyclin) with conventional therapy for primary pulmonary hypertension. N Engl J Med. 1996;334:296-301.

7. Barst RJ, McGoon M, McLaughlin V, et al. Beraprost therapy for pulmonary arterial hypertension. J Am Coll Cardiol. 2003;41:2119-2125.

8. Rubin LJ, Badesch DB, Barst RJ, et al. Bosentan therapy for pulmonary arterial hypertension. N Engl J Med. 2002;346:896-903.

9. Humbert M, Barst RJ, Robbins IM, et al. Combination of bosentan with epoprostenol in pulmonary arterial hypertension: BREATHE-2. Eur Respir J. 2004;24:353-359.

10. Galie N, Beghetti M, Gatzoulis MA, et al. Bosentan therapy in patients with Eisenmenger syndrome: a multicenter, double-blind, randomized, placebo-controlled study. Circulation. 2006;114:48-54.

11. Channick RN, Simonneau G, Sitbon O, et al. Effects of the dual endothelin-receptor antagonist bosentan in patients with pulmonary hypertension: a randomised placebo-controlled study. Lancet. 2001;358:1119-1123.

12. Galie N, Rubin L, Hoeper M, et al. Treatment of patients with mildly symptomatic pulmonary arterial hypertension with bosentan (EARLY study): a double-blind, randomised controlled trial. Lancet. 2008;371:2093-2100.

13. Jing ZC, Yu ZX, Shen JY, et al. Vardenafil in pulmonary arterial hypertension: a randomized, double-blind, placebo-controlled study. Am J Respir Crit Care Med. 2011;183:1723-1729.

14. Tapson VF, Torres F, Kermeen F, et al. Oral treprostinil for the treatment of pulmonary arterial hypertension in patients on background endothelin receptor antagonist and/or phosphodiesterase type 5 inhibitor therapy (the FREEDOM-C study): a randomized controlled trial. Chest. 2012;142:1383-1390.

15. Tapson VF, Jing ZC, Xu KF, et al. Oral treprostinil for the treatment of pulmonary arterial hypertension in patients receiving background endothelin receptor antagonist and phosphodiesterase type 5 inhibitor therapy (the FREEDOM-C2 study): a randomized controlled trial. Chest. 2013;144:952-958.
16. Jing ZC, Parikh K, Pulido T, et al. Efficacy and safety of oral treprostinil monotherapy for the treatment of pulmonary arterial hypertension: a randomized, controlled trial. Circulation. 2013;127:624-633.

17. Hoeper MM, Leuchte H, Halank M, et al. Combining inhaled iloprost with bosentan in patients with idiopathic pulmonary arterial hypertension. Eur Respir J. 2006;28:691-694.

18. McLaughlin VV, Gaine SP, Barst RJ, et al. Efficacy and safety of treprostinil: an epoprostenol analog for primary pulmonary hypertension. J Cardiovasc Pharmacol. 2003;41:293-299.

19. McLaughlin VV, Oudiz RJ, Frost A, et al. Randomized study of adding inhaled iloprost to existing bosentan in pulmonary arterial hypertension. Am J Respir Crit Care Med. 2006;174:1257-1263.

20. Ghofrani HA, Galie N, Grimminger F, et al. Riociguat for the treatment of pulmonary arterial hypertension. N Engl J Med. 2013;369:330-340.

21. Barst RJ, Oudiz RJ, Beardsworth A, et al. Tadalafil monotherapy and as add-on to background bosentan in patients with pulmonary arterial hypertension. J Heart Lung Transplant. 2011;30:632-643.

22. Wilkins MR, Paul GA, Strange JW, et al. Sildenafil versus Endothelin Receptor Antagonist for Pulmonary Hypertension (SERAPH) study. Am J Respir Crit Care Med. 2005;171:1292-1297.

23. Pulido T, Adzerikho I, Channick RN, et al. Macitentan and morbidity and mortality in pulmonary arterial hypertension. $N$ Engl $J$ Med. 2013;369:809-818.

24. Simonneau G, Barst RJ, Galie N, et al. Continuous subcutaneous infusion of treprostinil, a prostacyclin analogue, in patients with pulmonary arterial hypertension: a double-blind, randomized, placebo-controlled trial. Am J Respir Crit Care Med. 2002;165:800-804.

25. Simonneau G, Rubin LJ, Galie N, et al. Addition of sildenafil to long-term intravenous epoprostenol therapy in patients with pulmonary arterial hypertension: a randomized trial. Ann Intern Med. 2008;149:521-530.

26. Galie N, Ghofrani HA, Torbicki A, et al. Sildenafil citrate therapy for pulmonary arterial hypertension. $N$ Engl J Med. 2005;353:2148-2157.

27. McLaughlin VV, Benza RL, Rubin LJ, et al. Addition of inhaled treprostinil to oral therapy for pulmonary arterial hypertension: a randomized controlled clinical trial. J Am Coll Cardiol. 2010;55:1915-1922.

28. Hiremath J, Thanikachalam S, Parikh K, et al. Exercise improvement and plasma biomarker changes with intravenous treprostinil therapy for pulmonary arterial hypertension: a placebo-controlled trial. $J$ Heart Lung Transplant. 2010;29:137-149.

29. Galie N, Barbera JA, Frost AE, et al. Initial Use of Ambrisentan plus Tadalafil in Pulmonary Arterial Hypertension. $N$ Engl $J$ Med. 2015;373:834-844.

30. Zhuang Y, Jiang B, Gao H, Zhao W. Randomized study of adding tadalafil to existing ambrisentan in pulmonary arterial hypertension. Hypertens Res. 2014;37:507-512.

31. Galie N, Muller K, Scalise AV, Grunig E. PATENT PLUS: a blinded, randomised and extension study of riociguat plus sildenafil in pulmonary arterial hypertension. Eur Respir J. 2015;45:1314-1322.

32. McLaughlin V, Channick RN, Ghofrani HA, et al. Bosentan added to sildenafil therapy in patients with pulmonary arterial hypertension. Eur Respir J. 2015;46:405-413.
Patient Preference and Adherence

\section{Publish your work in this journal}

Patient Preference and Adherence is an international, peer-reviewed, open access journal that focuses on the growing importance of patient preference and adherence throughout the therapeutic continuum. Patient satisfaction, acceptability, quality of life, compliance, persistence and their role in developing new therapeutic modalities and compounds to optimize

\section{Dovepress}

clinical outcomes for existing disease states are major areas of interest for the journal. This journal has been accepted for indexing on PubMed Central. The manuscript management system is completely online and includes a very quick and fair peer-review system, which is all easy to use. Visit http://www. dovepress.com/testimonials.php to read real quotes from published authors. 